\title{
ALINHAMENTO ENTRE A ESTRATÉGIA DO NEGÓCIO E A GESTÃO DO RELACIONAMENTO COM O CLIENTE: CASO DE UMA EMPRESA DE TELEFONIA
}

\section{ALIGNMENT BETWEEN A BUSINESS STRATEGY AND THE CUSTOMER RELACIONSHIP MANAGEMENT: CASE OF A PHONE COMPANY}

\author{
Evandro Prieto \\ Consultor de empresas \\ Escola Politécnica da USP - Engenharia de Produção \\ TelFax(011) 30915363 R. 423 E-mail: prieto.evandro@gmail.com \\ Fernando José Barbin Laurindo \\ Professor Doutor \\ Escola Politécnica da USP - Engenharia de Produção \\ Tel (011) 30915363 R. 454 Fax 30915399 E-mail: fjblau@usp.br \\ Marly Monteiro de Carvalho \\ Professora Doutora \\ Escola Politécnica da USP - Engenharia de Produção
}

Tel (011) 30915363 R. 303 Fax 30915399 E-mail: marlymc@usp.br

RESUMO

O objetivo deste trabalho é discutir o alinhamento estratégico entre o negócio e clientes como principal fator na definição de vantagens competitivas sustentáveis. Dentro desta realidade considera-se o CRM (Gestão de Relacionamento com Clientes - Customer Relationship Management) como ferramenta estratégica para viabilizar este alinhamento. A metodologia utilizada foi o estudo de caso em uma empresa de telefonia com o objetivo de compreender a evolução e estágio que se encontra este alinhamento. A pesquisa evidenciou um deslocamento da estratégia de produção em massa para customização em massa como meio de adaptação às exigências de mercado.

Palavras-chave: Alinhamento estratégico, Gestão do relacionamento com clientes, Estabilidade Dinâmica. 


\begin{abstract}
The aim of this paper is to discuss the strategic alignment between business and customers' need as a critical factor in the definition and creation of sustainable competitive advantage. By this point of view, the CRM (Customer Relationship Management) is considered as a strategic tool to make possible this alignment. The methodology selected to conduct this work was the case study in a phone company. The objective is to investigate the evolution and the stage of the alignment. The research showed a movement process from the mass production to the mass customization market approach.
\end{abstract}

Key-words: Strategic Alignment, Customer Relationship Management, Dynamic Stability.

\title{
1. INTRODUÇÃO
}

As empresas do setor de telefonia estão passando por uma transformação, descartando o velho paradigma da Produção em Massa e caminhando em direção da Customização em Massa. O velho paradigma era caracterizado por esforços em fabricar produtos ou serviços padronizados para mercados homogêneos, cuja eficiência era atribuída à estabilidade e ao controle. Uma vez que seus mercados não são mais estáveis, não podem ser controlados e, portanto, suas operações não podem manter a eficiência do método antigo. Mercados homogêneos estão desaparecendo e dando lugar a uma nova configuração de instabilidade dinâmica nas organizações e de maior competitividade na busca pela fidelização de clientes.

Esta nova realidade de mercado leva a uma nova concepção da Cadeia de Valor que aplica a tecnologia e o conceito de Customer Relationship Management (CRM) de forma integrada em direção à Customização em Massa, ou seja, impulsiona transformações constantes nos processos, grande variedade e ciclos curtos de vida dos produtos. O CRM direciona a organização para a perspectiva estratégica denominada nível de serviços (HENDERSON \& VENKATRAMAN, 1993 apud LAURINDO, 2002).

O artigo aborda entre outros aspectos o novo cenário de competitividade e a necessidade de uma nova perspectiva de alinhamento estratégico dos negócios; a aplicação estratégica da tecnologia de CRM como meio de adaptação a mercados mais competitivos e instáveis e a análise do mercado brasileiro de telefonia. 


\section{PERCEPÇÃO DO NOVO CENÁRIO DE COMPETITIVIDADE - ALINHAMENTO ENTRE ESTRATÉGIA DO NEGÓCIO E GESTÃO DO RELACIONAMENTO COM O CLIENTE}

Vive-se um período de grandes mudanças em que mercados homogêneos estão desaparecendo e ao mesmo tempo dão lugar a mercados instáveis e de maior competitividade.

Pine (1993) define turbulência de mercado como sendo um "fenômeno de mudança" generalizada no ambiente de negócios atingindo mercados, demanda de clientes, tecnologias, domínios de mercado, produtos e processos.

Como destaca Pine (1994), o novo paradigma emergente da Customização em Massa caracteriza-se pela variedade e personalização, suplantando os produtos padronizados, pelo surgimento de mercados heterogêneos e fragmentados no lugar dos mercados homogêneos de outrora e pela acelerada redução do ciclo de desenvolvimento e de vida dos produtos, criando variedade e personalização através da flexibilidade e respostas rápidas aos consumidores. Os processos são mais importantes do que os produtos, e os consumidores em mercados heterogêneos crescentes demandam produtos personalizados.

Boynton, Victor e Pine (1991) consideram que a turbulência no mercado exige que as empresas caminhem na direção de uma estabilidade dinâmica em suas operações. Os mesmos autores propõem que a adequação das empresas a esta realidade de mercado depende da evolução e do estágio do alinhamento entre a estratégia de negócio e a Gestão do Relacionamento com Clientes. Estes autores (BOYNTON; VICTOR; PINE, 1991) apresentam uma matriz de análise de mudanças nos produtos e processos que deve ocorrer durante este processo de adaptação para atingir-se a estabilidade dinâmica e assim atender os mercados em crescente turbulência - vide Quadro 1. O estágio de estabilidade dinâmica também é denominado de estágio de Customização em Massa. O estágio de customização em massa pressupõe um alinhamento entre as estratégias de produto, estratégias de processo e as de tecnologias de informação empregadas. Tal alinhamento visa atender as demandas de mercado com foco na diferenciação de produtos (serviços) e flexibilização dos processos produtivos.

Os mesmos autores alertam que a passagem do quadrante de Produção em Massa para o de Customização em Massa não deve ser abrupta, mas gradual. Neste processo de transição, a empresa deve permanecer algum tempo no quadrante de Melhoria Contínua dos processos até estabilizá-los de forma a comportar a dinâmica dos produtos e serviços exigidos 
pela turbulência do mercado e a partir desta etapa, estabilizar-se no quadrante de Customização em Massa.

Quadro 1: Modelo de estabilidade dinâmica - principais características das estratégias na matriz de mudança produto-processo

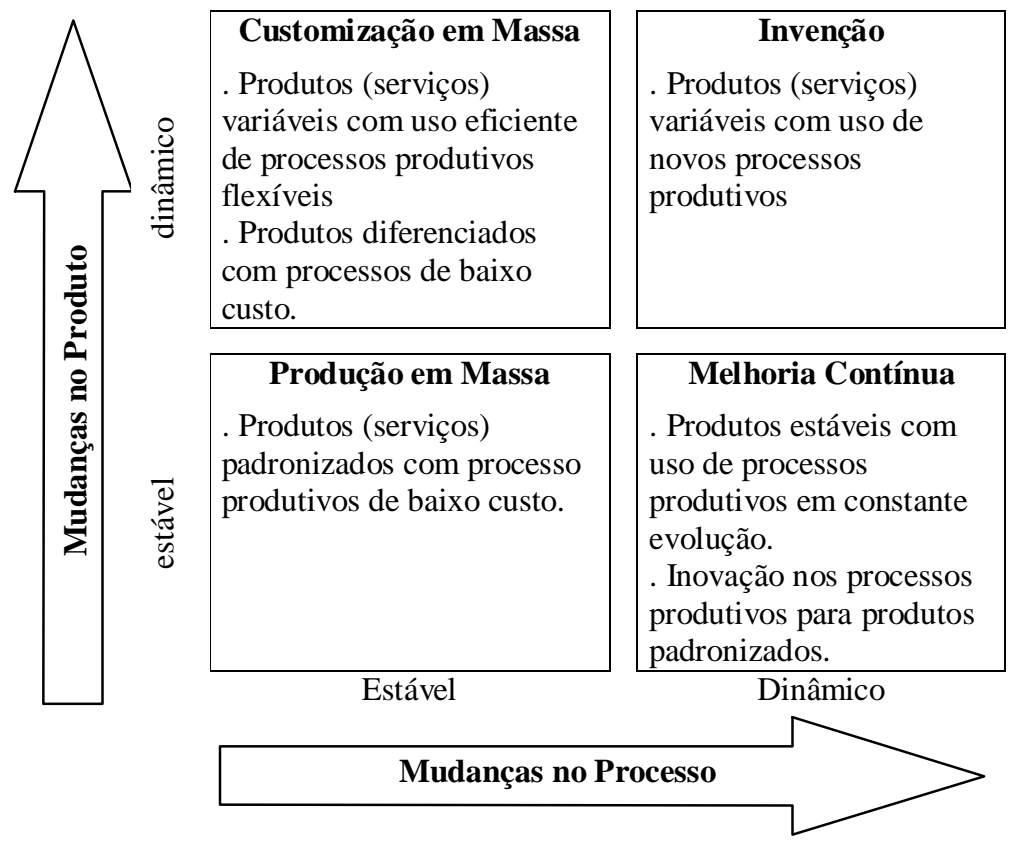

Fonte: Boynton, Victor e Pine (1993)

Pine (1994) considera que a TI é a engrenagem motora para a evolução das empresas de acordo com o Modelo de Estabilidade Dinâmica. A opinião de Pine (1994) está em consonância com Porter (1989) que por meio de seu Modelo da Cadeia de Valor também considera o uso da TI como uma ferramenta estratégica para a realização de mudanças que podem cooperar no alcance de maior competitividade. Henderson e Venkatraman (1993) apud Laurindo (2002) corroboram com as propostas de Porter (1989) e Pine (1994) do ponto de vista de um enfoque na medição do grau de alinhamento estratégico em relação às transformações constantes nos mercados. Estes autores propõem quatro critérios chave para avaliar o alinhamento das operações produtivas e de seus serviços em mercados de grande competitividade, que são: 1- execução da estratégia (custos / centros de serviços); 2transformação tecnológica (liderança tecnológica); 3- potencial competitivo (liderança de negócios) e 4-nível de serviços (satisfação dos clientes da TI, i.e, os usuários). A medição dos 
resultados da implementação de uma estratégia de adaptação aos mercados sensíveis às ofertas de produtos customizados e que, por sua vez, estão em constante mudança, depende dos seguintes aspectos: aplicação de tecnologias que contribuam para as melhorias organizacionais, adoção de inovações tecnológicas que garantam a crescente competitividade, a busca de liderança no segmento de atuação seja pela diferenciação ou custos competitivos e a crescente qualidade no nível dos serviços. (HENDERSON; VENKATRAMAN, 1993)

De acordo com a revisão bibliográfica sobre TI e dos fatores que podem medir o alinhamento das operações produtivas e serviços, considera-se que a opção por uma analogia com o critério de medição do nível de serviços seja a mais adequada para mercados sensíveis a ofertas de produtos customizados.

Neste sentido, a perspectiva de alinhamento estratégico de nível de serviços (HENDERSON; VENKATRAMAN,1993) foi analisada e comparada com a perspectiva de construção da cadeia de valor ao cliente (PORTER; MILLAR, 1985) e com o modelo de estabilidade dinâmica (Quadro 1). Estes modelos podem ser usados de maneira complementar e alinhados com as necessidades de adaptação e evolução organizacional em direção ao estágio de Customização em Massa.

A figura 1 mostra a correlação existente entre estes três modelos. Especificamente para este trabalho, o alinhamento estratégico de nível de serviços pode ocorrer por meio de uma estratégia de TI com visão $360^{\circ}$ (GALBREATH e ROGERS,1999). Entre as possibilidades de utilização de recursos de TI para atender a esta perspectiva $\left(360^{\circ}\right)$, a implementação do conceito e da tecnologia de CRM (Gestão do Relacionamento com o Cliente) surge como alternativa para atender às necessidades medição do nível de serviços nos processos de mudança e melhoria nas operações e oferta de produtos e serviços customizados. O conceito de CRM é um sistema de gerenciamento de processos, recursos informacionais, e das necessidades de pessoas para criar um ambiente que os negócios passem a ter uma "visão 360” graus dos seus consumidores (GALBREATH; ROGERS,1999).

Conforme apresentado na Figura 1, o princípio da tecnologia de CRM é a viabilização de um deslocamento progressivo das operações internas em direção a logística externa, marketing e vendas e serviços. 


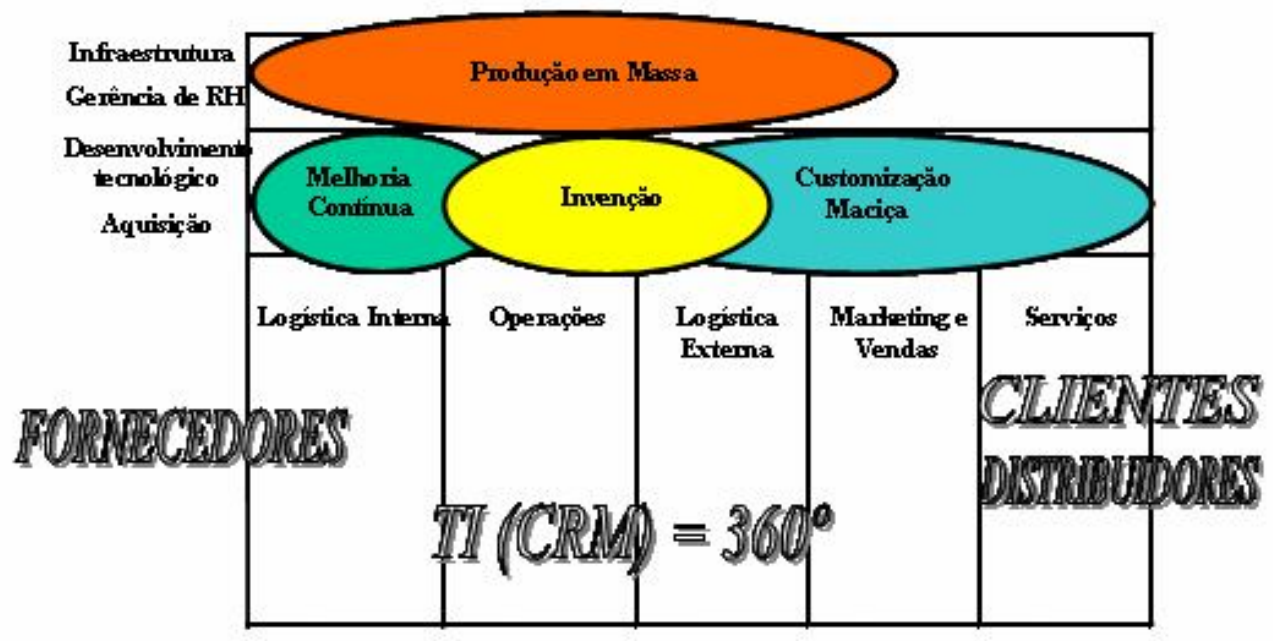

Figura 1: Correlação entre estabilidade dinâmica, cadeia de valor e TI (CRM)

Fonte: Adaptado de Escrivão Filho (2004) e Galbreath e Rogers (1999)

Pode-se assim fazer uma analogia com o alinhamento estratégico em nível de serviços, que visa à construção de uma organização classe mundial em serviços de sistemas de informação. O papel da estratégia de negócios é indireto, estimulando e atendendo a demanda dos clientes da TI. O critério de desempenho baseia-se na satisfação do cliente, obtida através de medidas quantitativas e qualitativas nos âmbitos interno e externo. Tal alinhamento, com os clientes da empresa, pode ser viabilizado através da tecnologia de CRM.

\subsection{Aplicação estratégica do conceito de CRM e o objetivo do Estudo de Caso}

O presente trabalho tem por objetivo discutir e analisar a evolução do alinhamento da estratégia do negócio em direção a satisfação de seus clientes, tendo como base um estudo de caso (YIN, 1991) em uma empresa de telefonia. A pesquisa foi realizada utilizando-se entrevista semi-estruturada com os executivos envolvidos na implementação da estratégia.

No quadro 2, estão descritos os "Determinantes do CRM" que orientam a empresa na direção da Customização em Massa.

O CRM pode ser classificado em três categorias: operacional, colaborativo e analítico. O CRM operacional está focado na eficiência das operações de logística interna e produção. 
Quadro 2: Determinantes do CRM

Determinantes do CRM - Gestão do Relacionamento com Clientes

\begin{tabular}{|c|c|c|c|c|}
\hline $\begin{array}{c}\text { Capturando os Clientes } \\
\text { certos }\end{array}$ & \begin{tabular}{|c|} 
Construindo a \\
proposição correta de \\
valor
\end{tabular} & $\begin{array}{c}\text { Instituindo os melhores } \\
\text { processos }\end{array}$ & $\begin{array}{l}\text { Motivando os } \\
\text { empregados }\end{array}$ & $\begin{array}{l}\text { Aprendendo a reter } \\
\text { clientes }\end{array}$ \\
\hline \multicolumn{5}{|c|}{ Isso acontece quando... } \\
\hline $\begin{array}{l}\text { Identifica-se os clientes } \\
\text { de maior valor }\end{array}$ & $\begin{array}{c}\text { Estuda-se quais produtos } \\
\text { ou serviços seus } \\
\text { consumidores precisam } \\
\text { hoje e no futuro }\end{array}$ & \multirow{2}{*}{$\begin{array}{l}\text { Pesquisa-se a melhor } \\
\text { forma de entregar seus } \\
\text { produtos e serviços aos } \\
\text { clientes, incluindo as } \\
\text { tecnologias necessárias } \\
\text { para investir, e, as } \\
\text { competências } \\
\text { necessárias para } \\
\text { desenvolver ou adquirir. }\end{array}$} & $\begin{array}{l}\text { São conhecidos quais as } \\
\text { ferramentas que seus } \\
\text { empregados precisam } \\
\text { para favorecer o } \\
\text { relacionamento com os } \\
\text { clientes }\end{array}$ & $\begin{array}{c}\text { Aprende-se porque os } \\
\text { seus clientes "o trairam"e } \\
\text { como conquistá-los } \\
\text { novamente }\end{array}$ \\
\hline $\begin{array}{c}\text { Calcula-se seu share no } \\
\text { bolso de cada cliente } \\
\text { para cada um de seus } \\
\text { produtos e serviços }\end{array}$ & $\begin{array}{l}\text { São pesquisados quais } \\
\text { produtos ou serviços } \\
\text { seus concorrentes } \\
\text { oferecem hoje e no futuro }\end{array}$ & & $\begin{array}{c}\text { Identifica-se quais } \\
\text { sistemas de RH são } \\
\text { necessários para } \\
\text { implementar co objetivo } \\
\text { de aumentar a lealdade } \\
\text { do cliente } \\
\end{array}$ & $\begin{array}{c}\text { Analisar o que seus } \\
\text { concorrentes estão } \\
\text { fazendo para conquistar } \\
\text { os seus clientes de alto } \\
\text { valor }\end{array}$ \\
\hline \multicolumn{5}{|c|}{ As tecnologias de CRM podem ajudar.... } \\
\hline $\begin{array}{c}\text { Analisar receitas e custos } \\
\text { dos clientes para } \\
\text { identificar quais os } \\
\text { consumidores de maior } \\
\text { valor atuais e futuros }\end{array}$ & $\begin{array}{c}\text { Coletar dados } \\
\text { comportamentais } \\
\text { referentes a produtos ou } \\
\text { serviços }\end{array}$ & $\begin{array}{c}\text { Processos transacionais } \\
\text { mais rápidos }\end{array}$ & $\begin{array}{l}\text { Definir alinhamento das } \\
\text { atividades e métricas }\end{array}$ & $\begin{array}{c}\text { Identificar uma escala de } \\
\text { perda e retenção de } \\
\text { clientes }\end{array}$ \\
\hline $\begin{array}{l}\text { Focar melhor seus } \\
\text { esforços de marketing }\end{array}$ & $\begin{array}{l}\text { Criar novos canais de } \\
\text { distribuição }\end{array}$ & $\begin{array}{l}\text { Fornecer informações } \\
\text { mais importantes ao } \\
\text { pessoal da linha de } \\
\text { frente }\end{array}$ & $\begin{array}{l}\text { Desdobrar sistemas de } \\
\text { gestão do conhecimento }\end{array}$ & $\begin{array}{c}\text { Identifica níveis de } \\
\text { satisfação dos serviços } \\
\text { ao cliente }\end{array}$ \\
\hline
\end{tabular}

Fonte: Avoid the Four Perils of CRM, by Darrel K. Rigby, Frederick F. Reichheld, and Phil Schefter, HBR, (Fevereiro de 2002)

Do ponto de vista do CRM estratégico (analítico e colaborativo) os canais de comunicação são utilizados e análises de oportunidades com os clientes que possibilitam a customização em larga escala de produtos e serviços. Outra e atender demandas diferenciadas de produtos através de variedade, bem como permite determinar quem são os clientes, quais devem ser tratados de forma personalizada, one-to-one, e quais são os clientes que devem ser deslocados para níveis de prioridade inferior.

Cabe observar que conforme a organização evolui na direção da Customização em Massa, as características estratégicas incorporam os "Determinantes do CRM" como fatores de sucesso. 


\section{MERCADO BRASILEIRO DE TELEFONIA}

O mercado brasileiro de telefonia apresentou profundas modificações desde as privatizações que tiveram seu início em 1998. O antigo modelo estatal e monopolista deu lugar a outro privado e concorrencial que apresenta um grau relativamente alto de desenvolvimento, bem como uma forte competição entre as empresas atuantes.

Após a privatização formaram-se três "incumbents" de telefonia fixa local (Telemar, Telefônica e Brasil Telecom) e uma "incumbent" de telefonia de longa distância (Embratel). Houve uma grande expansão tanto do parque de telefones fixos quanto de telefones móveis.

O setor brasileiro de telecomunicações pode ser dividido em quatro mercados interrelacionados: telefonia fixa, telefonia móvel, telefonia de longa distância e transmissão de dados. O mercado de telefonia fixa atingiu seu estado de maturação com 10,5 milhões de linhas em serviço e 38,9 milhões em reserva em 2003. O mercado de telefonia móvel superou o mercado de telefonia fixa em número de linhas em serviço no ano de 2003, totalizando 38 milhões. Os mercados de transmissão de dados e ligação de longa distância estão no início do ciclo de crescimento (ANGRISANO \& LAURINDO, 2004).

O quadro atual é de grandes oportunidades e grandes ameaças para os atuais grupos estratégicos. Novos concorrentes estão entrando no mercado e os consumidores, cada vez mais, com maior poder de barganha.

\section{ESTUDO DO CASO}

O estudo de caso foi desenvolvido em uma empresa de telefonia com o objetivo de identificar as estratégias de CRM que estão impulsionando o alinhamento entre a estratégia do negócio e a gestão do relacionamento com o cliente, desde o início da privatização do setor até o momento, sendo descritas principais opções estratégicas adotadas.

\subsection{Aumento da teledensidade}

Após a quebra do modelo monopolista, a empresa foco do estudo começou suas operações com uma grande base de clientes em um mercado de pouca concorrência e uma estrutura organizacional com boa parte de seus colaboradores com formação técnica. 
Os investimentos concentraram-se no aumento da teledensidade (proporção do número de linhas em serviço sobre a população). Em conseqüência disto, tanto a eficácia de seu sistema de operações como sua imagem perante o público ficaram bastante prejudicadas.

A qualidade dos serviços prestados, principalmente à pessoa física teve uma queda expressiva.

\subsection{Excelência operacional e enfoque comercial}

Após o cumprimento das metas de universalização, a estratégia dos negócios concentrou-se em investimentos na eficácia de seus sistemas operacionais. Os ativos foram modernizados, foram realizados investimentos em novas tecnologias de terminais voltados ao segmento empresarial e foram determinadas novas competências para os colaboradores, voltadas para o atendimento do cliente e prestação de novos serviços. Um Call Center de pós venda foi implementado e monitorado pelo uso de indicadores de eficiência operacional, tais como, velocidade de atendimento e percentual de chamadas atendidas e transferidas. Em paralelo um processo de implementação de Sistema de Banco de Dados (DBM) foi definindo, bem como duas segmentações de clientes (Pessoa Jurídica e Pessoa Física) para a construção de camadas de informações de maior profundidade.

Com a utilização dessa base de clientes, a oferta de produtos e serviços começou a ser focada nas necessidades destes segmentos, mas sem uma integração entre as diversas bases de dados de toda organização. Neste contexto, as deficiências nos serviços ao cliente persistiram.

\subsection{Foco nas necessidades dos clientes}

No ano de 2004, após processo de reestruturações a empresa passou a ter cinco vicepresidências: comercial, de empresas médias e pequenas, corporativa, de rede e engenharia e TI. Estas áreas possuem estruturas administrativas e unidades de Call Centers próprios a clientes com ênfase no cumprimento de metas comerciais e resolução de casos de insatisfação.

Além destas centrais de atendimento, possui outra de suporte técnico para solução de defeitos na infra-estrutura tecnológica externa.

Recentemente estabeleceram metas de superação das expectativas dos clientes em toda a América Latina e passaram a aplicar pesquisas padronizadas que são aplicadas de seis 
em seis meses, com o objetivo medir, adequar e otimizar processos para atingir as expectativas dos clientes.

Está em andamento uma análise mais profunda de estratificação da base de clientes e a identificação de seus hábitos e interesses de consumo.

A estratégia de foco nas necessidades é impulsionada através de substituição e integração de todo o sistema de informações da empresa, bem como através de lançamento de novos produtos e serviços. Tais medidas estão fortalecendo suas vantagens competitivas atuais.

Programas de conscientização sobre importância dos clientes e programas de qualidade como Seis Sigma e ISO 9000 estão sendo implementados com objetivos de diminuição de custos e melhoria dos processos.

\section{ANÁLISE DO CASO}

A empresa está se estruturando na direção da satisfação dos clientes e sua conseqüente fidelização. Após a expansão e estabilização de sua base de clientes, está buscando melhorar o desempenho operacional e incrementar os resultados de vendas. Também está realizando esforços para garantir lançamentos de novos produtos e serviços e terá como grande desafio alcançar uma Customização em Massa.

A estrutura de CRM definida pelos Call Centers ainda está voltada para a diminuição dos custos operacionais por cliente, ou seja, foco na eficiência.

O conhecimento contínuo e crescente sobre as necessidades dos clientes indica uma opção em direção ao CRM estratégico e seus respectivos determinantes de forma gradual. A estratégia do negócio e seu alinhamento com a gestão do relacionamento com o cliente atravessam um processo gradual de evolução que possibilita a manutenção da lucratividade, a longo prazo, a seus stakeholders.

Algumas ações de CRM estratégicas têm se voltado para o conhecimento das necessidades dos clientes, como pesquisas semestrais de satisfação, que estão determinando mudanças nos processos internos da organização e adequação das competências de seus recursos humanos.

A busca de maior desempenho operacional tende a estabilizar os processos de forma a comportar as exigências da dinâmica de constantes lançamentos de produtos e oferta de serviços. 
A empresa tem analisado possíveis posicionamentos estratégicos para os próximos anos em relação à sua forma avaliação de desempenho do negócio. Sem pretender aprofundar esta questão, o raciocínio financeiro tem prevalecido através da adoção do Lucros e Perdas (PNL) como medida de desempenho das operações e tal conceito faz parte do alinhamento de Execução da Estratégia. O conceito de CRM que estabelece um raciocínio da obtenção de lucro por cliente leva a organização a refletir como tornar os clientes cada vez mais satisfeitos em um ambiente de turbulência e hiper competição sem dificultar a gestão do negócio. $\mathrm{O}$ ciclo de vida dos produtos tem diminuído ao longo do tempo e provocando elevados custos de lançamento.

\section{CONCLUSÕES}

Este estudo abordou a evolução e estágio do alinhamento entre a estratégia de negócio e a gestão do relacionamento com clientes, levando-se em consideração as mudanças do mercado e as opções estratégicas da empresa.

Evidenciou-se que a empresa analisada está na direção da customização em massa de acordo com a evolução de mudanças nos processos internos e na crescente oferta de produtos diferenciados. As fases de evolução nos negócios da empresa analisada puderam evidenciar sua adaptação às necessidades do mercado.

A fase inicial de aumento da teledensidade caracteriza a busca da produção em massa associada a custos menores de produção em comparação aos obtidos anteriormente. A busca da excelência operacional evidenciou-se pelos investimentos na padronização dos processos e a oferta de uma linha de produtos de maior sinergia entre as suas diversas categorias. $\mathrm{O}$ enfoque comercial e o progressivo conhecimento do perfil e das necessidades dos clientes que se caracterizou pela criação de novas unidades de negócio para tipos específicos de clientes impulsionaram o potencial de utilização da estratégia de CRM. Apesar do alinhamento entre a estratégia do negócio e a gestão de relacionamento com os clientes tenham sido alcançados através de esforços não integrados entre as diversas diretorias, a tecnologia de CRM tem possibilitado a avaliação de novas oportunidades de criação e oferta de produtos e serviços de maior valor aos clientes. 


\section{REFERENCIAS}

ANGRISANO, C. A.; LAURINDO, F.J.B. Modelo de análise setorial para apoio à tomada de decisões estratégicas: aplicação ao mercado brasileiro de telecomunicações. São Paulo: Escola Politécnica da USP, 2004. (Boletim Técnico).

BOYNTON, Andrew C.; BART, Victor; PINE II, B. Joseph. New competitive strategies: Challenges to organizations and information technology.1993. 22 f. IBM Systems Journal, v. 32, n. 1, p. 40-61. 1993.

ESCRIVÃO FILHO, Edmundo. Pensamento administrativo - customização maciça: Demanda e Produção Flexíveis. Disponível em: <http://www.uniara.com.br/especializacao/documentos/RH/EPA-Textos-em-\%20Aula.doc>. Acesso em: 20/12/2004.

GALBREATH, Jeremy e ROGERS, Tom. Customer Relationship Leadership: a leadership and motivational model for the twenty-first century business. TQM Magazine, vol. 11, n.3, p. 161-171, 1999.

HENDERSON, J.C. \& VENKATRAMAN, N. (1993); Strategic alignment: leveraging information technology for transforming organizations. IBM Systems Journal. v.32, n.1, p.416. In: Laurindo, F.J.B, 2002); Tecnologia da Informação: Eficácia nas Organizações. São Paulo, Ed. Futura, 248p.

LAURINDO F. J. B. Tecnologia da Informação: Eficácia nas Organizações São Paulo, Ed. Futura, 248p.

PINE II, Joseph et al. Making Mass Costumization Work. Harvard Business Review, sep./oct. 1993.

PINE, B. Joseph, Customização Maciça: A Nova Fronteira da Competição dos Negócios, Makron Books, 1994.

PORTER, M.E. How competitive forces shape strategy. Harvard Business Review, p. 137145, Nov./Dec., 1979 
\& MILLAR, V.E. How information gives you competitive advantage.

Harvard Business Review, v.63,n.4,p.149-160, Jul./Ago.1985

Rigby D. K., Reichheld F.F., Schefter P. \& RIGBY, D. K. Avoid the Four Perils of CRM. Harvard Business Review, feb, p. 94 - 101, 2002.

YIN, R.K. Case Study Research: Design and Methods. Newbury Park, Rev. ed. Sage Publications, 1991.

Artigo recebido em 19/09/2006 e publicado em 21/08/2007. 